\title{
GMR
}

\section{Protein expression and characterization of SEP3 from Arabidopsis thaliana}

\author{
Q. Shi, J. Zhou, P. Wang, X. Lin and Y. Xu \\ Nurturing Station for the State Key Laboratory of Subtropical Silviculture, Zhejiang \\ Agriculture and Forestry University, Lin'an, Zhejiang, China \\ Corresponding author: Y. Xu \\ E-mail: yxu@zafu.edu.cn
}

Genet. Mol. Res. 14 (4): 12529-12536 (2015)

Received April 30, 2015

Accepted August 11, 2015

Published October 16, 2015

DOI http://dx.doi.org/10.4238/2015.October.16.20

ABSTRACT. SEPALLATA (SEP) MADS-box genes play crucial roles in the regulation of floral growth and development. They are required for the specification of sepals, petals, stamens, and carpels as well as for floral determinacy. SEPs perform their functions through the formation of homoor hetero-polymers, which are the molecular basis of floral quartets. In vitro assays indicated that SEP3 forms a tetramer after binding to DNA, but it is unclear whether DNA binding induces the tetramer, because SEP3 is often reported to form a dimer. Here, we analyzed the oligomeric status of SEP3 domains in the absence of the DNA-binding MADS-box domain. The truncated SEP3 was constructed as a fusion protein and expressed in prokaryotic cells. The purified protein fragment displayed as a tetramer in the size exclusion chromatographic column, and a glutaraldehyde cross-linking assay demonstrated that the protein contained a dimer unit. Yeast two-hybrid tests further verified that the fragments form homologous polymers in vivo, and that the $\mathrm{K}$ domain is involved in tetramer formation. Current results imply that the SEP3 protein regulates the formation of flower meristems using the tetramer as a unit, and that the DNA-binding MADS-box is dispensable for polymer formation. The C-terminal region 
does not contribute to homo-tetramer formation, but it may be reserved to glue other proteins.

Key words: SEP3 protein; Tetramer; Yeast-two hybrid; Protein purification; Arabidopsis thaliana

\section{INTRODUCTION}

The MADS-box gene family plays crucial roles in plant development and flowering formation (Agrawal et al., 2005). To specify the floral organ identity, the five MADS-box gene classes interact in a combinational way to compose the well-known "floral quartet model". In this model, the $\mathrm{E}$ class MADS-box SEPALLATA3 (SEP3) is indispensable, and it plays central roles (Coen and Meyerowitz, 1991; Krizek and Meyerowitz, 1996). For instance, it interacts with other class $E$ genes and APETALA1 (AP1) to specify sepals, with AP1 and AP3-PISTILLATA (PI) to specify petals, with the AP3-PI-AGAMOUS (AG) complex to specify stamens, and with AG to specify carpels (Pelaz et al., 2000; Pelaz et al., 2001; Kaufmann et al., 2009). Chromatin immunoprecipitation and whole-genome hybridization arrays have shown that thousands of SEP3 binding sites lie in the floral organs, and that SEP3 integrates with these target MADS-box genes to control flower development (Kaufmann et al., 2009; Hwan Lee et al., 2012; Liu et al., 2014). In vitro DNA hybrid tests have shown that mammalian MADS-box transcription factors bind specific DNA elements in the promoter region, which are known as CC-A rich-GG (CArG-box). For example, the serum response factor ( $S R F)$ and myocyte enhancer factor 2A (MEF2A) MADS-box genes can bind the sequence CC(A/T)6GG (West et al., 1997; West et al., 1998). Similar to SRF and MEF2A, plant MADS-box transcription factors can also bind CArGbox-like sequences, and the binding region is mainly composed of the N-terminal MADS (M) domain (West et al., 1998). As a typical MADS-box protein, SEP3 contains M, intervening (I), keratin-like (K), and C-terminus (C) structural domains. Recent in vitro studies indicated that SEP3 proteins could bind to two CArG-boxes (Melzer et al., 2009; Jetha et al., 2014), suggesting a tetrameric construction of SEP3. However, it is unclear whether the tetrameric SEP3 is induced by DNA binding or if it is a homo-tetramer, because the ability of SEP3 to form dimers has been previously reported (Huang et al., 1996; Mendes et al., 2013). Additionally, indirect evidence suggests that SEP3 is a tetramer or a dimer when forming a homocomplex. A recently determined crystal structure of an SEP3 fragment (75-178 aa) revealed the mechanism of SEP3 tetramerization (Puranik et al., 2014). However, the purified protein fragment contained both dimer and tetramer components. Therefore, it is necessary to clarify if SEP3 forms homo-dimers or homo-tetramers, and the role of DNA binding in polymer formation must also be determined. Here we analyzed the oligomeric status for SEP3 domains without DNA binding regions. The proteins were expressed in prokaryotic cells, and were analyzed using a size exclusion chromatographic column. The results indicated that SEP3 forms tetramers, and that DNA binding is not required for SEP3 polymer formation. Our data also suggested that the $\mathrm{K}$ region plays a major role in mediating SEP3 self-association, and that the C-terminus may be reserved for gluing other MADS-box proteins.

\section{MATERIAL AND METHODS}

\section{Material}

We used the plant Columbia Arabidopsis thaliana as our research subject. A yeast two- 
hybrid $(\mathrm{Y} 2 \mathrm{H})$ kit was purchased from Clontech (Beijing), and Trans1-T1 competent cells were obtained from Trans Gen Biotech (China). The PCR product purification kit was purchased from TaKaRa (China), and the plasmid extraction kit was acquired from Sangon (China). pET protein expression vectors were purchased from Novagen (Germany), and the remaining chemical reagents were domestic.

\section{Construction of SEP3 domain expression plasmids}

Total RNA was isolated from wild-type blossom buds using the TRIZOL reagent (China), and it was then reverse transcribed into cDNA. The open reading frame encoding SEP3 was amplified via PCR with the following upstream and downstream primer sequences: 5'-CATGTGCCATGG GAAGAGGGAGAGTAGAATTGA-3' and 5'-CGCGGATCCTTAAGTGAGAAAGATTCAAAT-3'. PCR was performed with a denaturation step at $94^{\circ} \mathrm{C}$ for $3 \mathrm{~min}$, followed by 30 cycles of $94^{\circ} \mathrm{C}$ for $30 \mathrm{~s}$, $56^{\circ} \mathrm{C}$ for $30 \mathrm{~s}, 72^{\circ} \mathrm{C}$ for $30 \mathrm{~s}$, and an extension at $72^{\circ} \mathrm{C}$ for $6 \mathrm{~min}$. The PCR product was T-A linked to a pMD-19 vector (TakaRa) to serve as a template. SEP3B (78-230 aa) and SEP3C (78-190 aa) were obtained by cloning the PCR products into the $\mathrm{pET} 15 \mathrm{~b}$ vector between the Nco1 and BamH1 restriction sites. The reverse primers for SEP3C and SEP3B were GGATCCTCAGTGATGATGATG ATGATGTTGGTTAGGGTTCAGCTGGA-3' and ATCCTCAGTGATGATGATGATGATGCATTCCAT CTTGTTGCCCCT-3', respectively. They both contained a non-cleavable 6XHis-tag before the stop codon. All constructs were transformed into the $\mathrm{DH} 5 \mathrm{a}$ strain, and the plasmids were extracted and confirmed via DNA sequencing.

\section{Over-expression and purification of His-tagged SEP3 domain proteins}

The recombinant plasmids were transferred to BL21 (DE3) Rosetta cells for over-expression analysis. To screen for optimal temperatures, $3 \mathrm{~mL}$ cell cultures were induced at $20^{\circ}$ and $37^{\circ} \mathrm{C}$. To scale up the expression system, $10 \mathrm{~mL}$ of freshly grown overnight cell cultures were used to inoculate $1 \mathrm{~L} \mathrm{LB}$ medium, which was induced by adding $0.1 \mathrm{mM} \mathrm{IPTG}$ at $20^{\circ} \mathrm{C}$ for $15 \mathrm{~h}$. The harvested cell pellets were resuspended in $10 \mathrm{~mL}$ lysis buffer $(0.5 \mathrm{M} \mathrm{NaCl}, 20 \mathrm{mM}$ Tris- $\mathrm{HCl}, \mathrm{pH}$ 8.0) on ice, and were lysed via ultrasonication for $10 \mathrm{~min}$ with an $8 \mathrm{~s}$ pulse or $10 \mathrm{~s}$ interval. Each sample was centrifuged for $40 \mathrm{~min}$ at a speed of $36,500 \mathrm{~g}$. The supernatant was incubated with $5 \mathrm{~mL}$ nickel beads on ice with slow rocking for $1 \mathrm{~h}$. To remove non-specific binding proteins, the beads were washed with a gradient concentration of imidazole $(4 / 20 / 80 \mathrm{mM})$ in buffer containing $200 \mathrm{mM} \mathrm{NaCl}, 20 \mathrm{mM}$ Tris- $\mathrm{HCl}, \mathrm{pH}$ 8.0. The target proteins were then eluted with $40 \mathrm{~mL} 200 \mathrm{mM}$ imidazole in $200 \mathrm{mM} \mathrm{NaCl}$ and $20 \mathrm{mM}$ Tris$\mathrm{HCl}, \mathrm{pH}$ 8.0. The proteins were concentrated to $500 \mu \mathrm{L}$ using an Amicon ultracentrifuge at $4^{\circ} \mathrm{C}$, and were then loaded onto the gel filtration column (Superpose 6) for final cleanup. The protein purity was checked by SDS-PAGE, and was quantified based on its optical absorbance coefficient at $280 \mathrm{~nm}$.

\section{Glutaraldehyde cross-linking}

In order to determine the homologous interactions within or between the different subunits, we performed a cross-linking reaction using glutaraldehyde, which is capable of cross-linking surface amine groups. His-tag proteins SEP3B and SEP3C were reacted with glutaraldehyde at a molar concentration ratio of $1: 10$ at $20^{\circ} \mathrm{C}$. Resulting $10 \mu \mathrm{L}$ samples were taken at different time points, and an equal volume of Tris- $\mathrm{HCl}$ buffer $(100 \mathrm{mM}, \mathrm{pH}$ 8.0) was added to terminate the reaction. The samples were separated by SDS-PAGE, and were detected using the silver staining method. 


\section{$\mathrm{Y} 2 \mathrm{H}$ assays}

$\mathrm{Y} 2 \mathrm{H}$ assays were used to determine which SEP3 domain plays the key role in polymer formation. The experiment was designed according to the Matchmaker GAL4 Two-Hybrid System (Clontech). Five SEP3 domains were PCR amplified with primers containing two restriction enzyme loci: EcoR1 and BamH1. After cleavage and purification, the inserts were ligated to a pGADT7AD vector containing the GAL4 activation domain (AD) or a pGBKT7 vector containing the DNA binding domain (BD). The prey recombinant plasmids (AD) were transferred into $\mathrm{AH} 109$ cells (Clontech), and bait vectors (BD) were transferred into $\mathrm{Y} 187$ cells (Clontech). $\mathrm{AD}$ and $\mathrm{BD}$ cells were incubated at $30^{\circ} \mathrm{C}$ on $\mathrm{SD} /$-Leu selective medium and $\mathrm{SD} /-$ Trp plates, respectively. AD cells were mixed with $B D$ cells and hybridized overnight. Selection of the hybrid clones was performed on SD/-Leu/-Trp plates, and protein interactions were detected on SD/-Leu/-Trp/-His/-Ade with X-a-Gal plates.

\section{RESULTS AND DISCUSSION}

\section{Protein expression and purification analysis}

The desired nucleotides of the full length SEP3 and the deletion construct SEP3C were verified by sequencing. The domain arrangement is shown in Figure $1 \mathrm{~A}$, and induction of the recombinant domain protein in E. coli was found to be more efficient at $20^{\circ} \mathrm{C}$ than at $37^{\circ} \mathrm{C}$. Although the target protein expression levels remained roughly the same, the soluble fraction tended to decrease at the higher temperature (Figure 1B). Therefore, the induction was performed at $20^{\circ} \mathrm{C}$. The full-length protein was not soluble under the tested conditions, and purification of the soluble recombinant protein was conducted through Ni-NTA affinity chromatography.

As shown in the SDS-PAGE results (Figure 1B), the SEP3C protein was eluted with a buffer containing $200 \mathrm{mM}$ imidazole, and the eluted protein was over $90 \%$ pure. Moreover, SEP3C migrated slightly faster than the $15 \mathrm{kDa}$ protein marker (Figure 1B), which was consistent with the estimated molecular weight of $13 \mathrm{kDa}$. The protein expression yield was high, and we constantly obtained over $4 \mathrm{mg}$ of pure protein from per liter of cell culture. The apparent protein size in solution was determined by size exclusion chromatography, which was calibrated by ovalbumin (43 kDa) and BSA (67 and $133 \mathrm{kDa}$ ) markers. As shown in Figure 2, SEP3C migrated with an apparent size of $\sim 50 \mathrm{kDa}$, demonstrating that the SEP3C domain is tetrameric in solution. Expression of the longer C-terminus construct, SEP3B, was previously reported (Zhou Jiaping, 2014), and it was also found to be tetrameric under similar conditions.

\section{Cross-linking analysis}

To confirm the oligomeric status, a glutaraldehyde cross-linking experiment was performed. As shown in Figure 3, dimer bands appeared after the 20 min incubation, and became denser with time. This was true for both SEP3B and SEP3C proteins. Although tetrameric bands were not observed, the results do not definitively indicate that the proteins are not tetrameric. Instead, the results suggest that the dimer part of the tetrameric protein is readily cross-linked. It may be true that the distribution of the amine groups on the three dimensional structure restricts the crosslinking of the tetramers. 


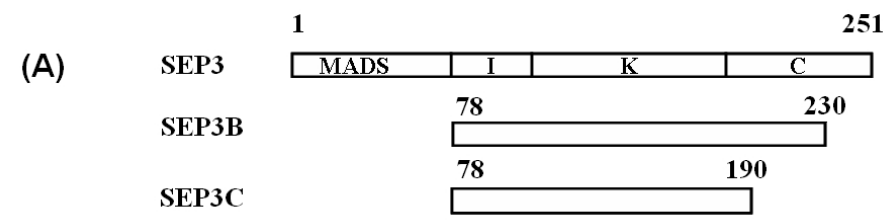

(B)

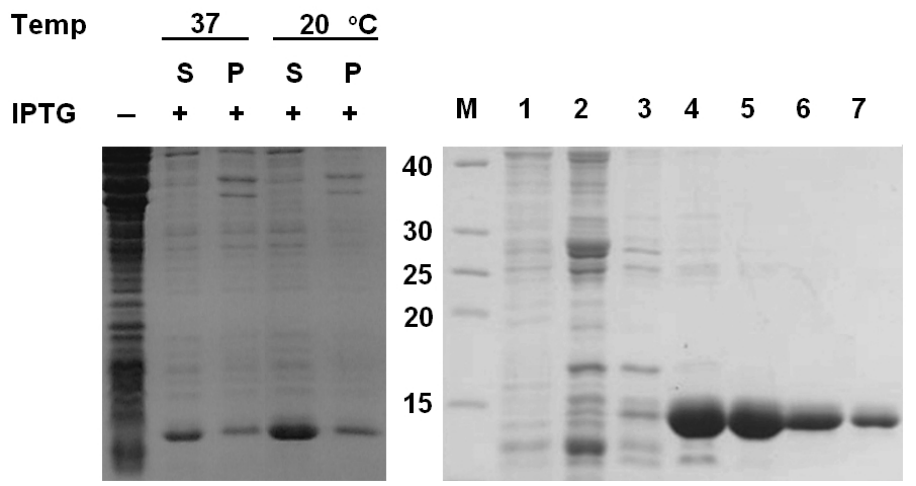

Figure 1. Illustrations of the SEP3 domain arrangement and protein expression profile. A. Full length SEP3 MADS-box protein, including MADS (M), intervening (I), keratin-like (K), and C-terminal (C) domains. SEP3C and SEP3B denote motifs with 78-190 aa and 78-230 aa, respectively. B. SDS-PAGE results show the induction (left) and purification (right) profiles. On the left gel, S and P denote the soluble and insoluble fractions, respectively. In the right, lanes 1-3 correspond to washes with 20,40, and $80 \mathrm{mM}$ imidazole, respectively, and lanes 4-7 correspond to elutions with 200 $\mathrm{mM}$ imidazole. $\mathrm{M}$ denotes the protein molecular-weight marker in $\mathrm{kDa}$.

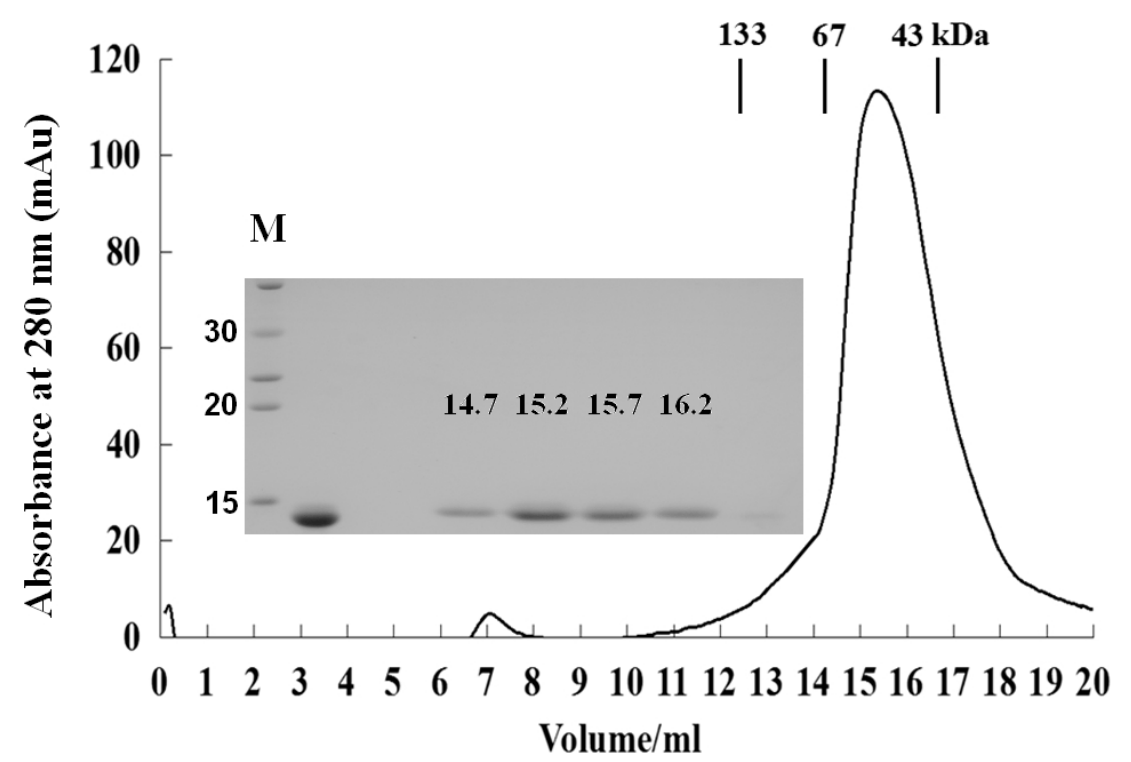

Figure 2. SEC profile for SEP3C protein. The SDS-PAGE insert corresponds to the SEC profile. The numbers match the elution fraction volume in SEC. M denotes the protein molecular-weight marker in $\mathrm{kDa}$. 


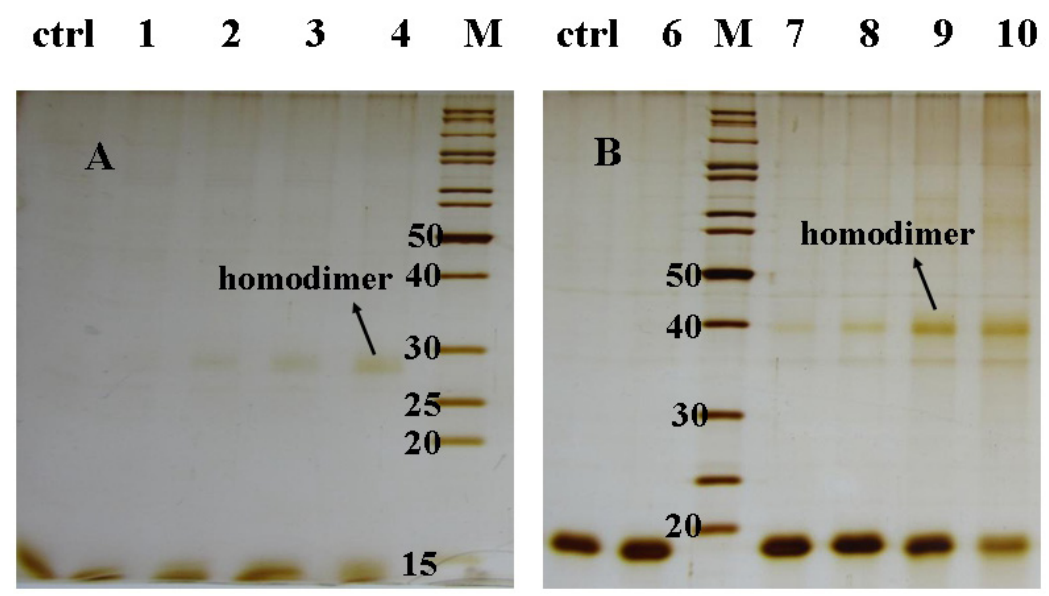

Figure 3. Glutaraldehyde cross-linking assays for the SEP3C and SEP3B proteins. The purified protein was incubated in either the absence or presence of glutaraldehyde at $20^{\circ} \mathrm{C}$. Silver stain was used to view SDS-PAGE results. (A) SEP3C. Lanes $1-4$ correspond to incubation times of $5 \mathrm{~min}, 20 \mathrm{~min}, 1 \mathrm{~h}$, and $5 \mathrm{~h}$, respectively. (B) SEP3B. Lanes 6-10 correspond to incubation times of $5 \mathrm{~min}, 20 \mathrm{~min}, 1 \mathrm{~h}, 5 \mathrm{~h}$, and $18 \mathrm{~h}$, respectively. Ctrl represents the control group that was free from the cross-linking reagent.

\section{Y2H analysis}

$\mathrm{Y} 2 \mathrm{H}$ experiments were performed to verify if the protein domains interacted in vivo and to determine which domain is vital to the interaction. The domain design is shown in Figure 4A. The $\mathrm{KC}$ motif construct showed strong auto-activation, so it was removed from the bait list. As expected, the positive and negative controls appeared as blue and white clones, respectively (Figure 4B). The presence of a blue spot verified that the full-length SEP3 formed a homocomplex (Figure 4B), which is consistent with a previous report (de Folter et al., 2005). The KC and IK domains formed interactions with the full length SEP3. The IK domain, close to the SEP3C construct, showed a weak but positive signal for the homo-interaction, which was consistent with the in vitro expression assay. However, the lack of interaction with any region was indicative of the unexpected appearance of the IKC motif. Although it was unclear why IKC lacked interactions, the $\mathrm{Y} 2 \mathrm{H}$ experiments results still suggested that the $\mathrm{K}$ domain outlines the core part of SEP3 tetramer formation. This is similar to many MADSbox proteins where the $\mathrm{K}$ domain mediates the internal complex formation (Yang and Jack, 2004; Leseberg et al., 2008). Recent crystal structure results revealed that four $\mathrm{K}$ domains were assembled together through their second helices, and the first helices made the dimer only (Puranik et al., 2014).

In the $\mathrm{Y} 2 \mathrm{H}$ experimental assay, the MI motif did not associate with any region. This result, together with the in vitro expression assay, suggests that the MADS-box M region is dispensable for tetrameric formation. In another words, the tetramer is not induced by DNA binding. The $\mathrm{Y} 2 \mathrm{H}$ experimental assay results also indicated that the C-terminal region was also not involved in the complex formation. This region is generally responsible for hetero-complex formation between different MADS-box proteins (Su et al., 2008; Immink et al., 2009). Therefore, the results suggest that the SEP3 C-terminus might be the glue that connects other proteins. Thus, deletion of the C-terminus amino acids will not change the oligomeric status, and the observed tetrameric property of SEP3B and SEP3C is intrinsic to the SEP3 homo-complex. However, a dimer complex was observed in the crystallized construct (75-178 aa) (Puranik et al., 2014), but not in SEP3C (78-190 
aa, Figure 2). This implies that residues between 178 and 190 contribute to tetramer stabilization. In short, our analysis demonstrated that SEP3 form homo-tetramers, mainly through $\mathrm{K}$ domain association. Neither the DNA-binding MADS-box nor the C-terminal region is required for the polymer formation. It is possible that the tetramer shape a platform to support the roles of $\mathrm{N}$ and C-terminal domains in the development of flower meristem.

(A)

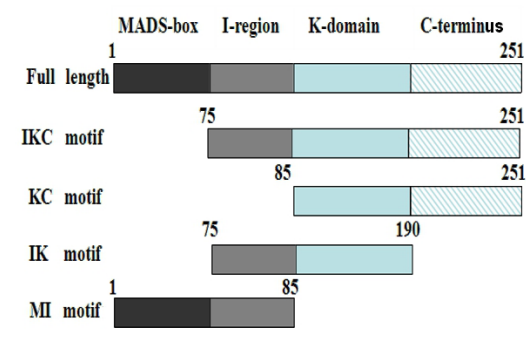

(B)
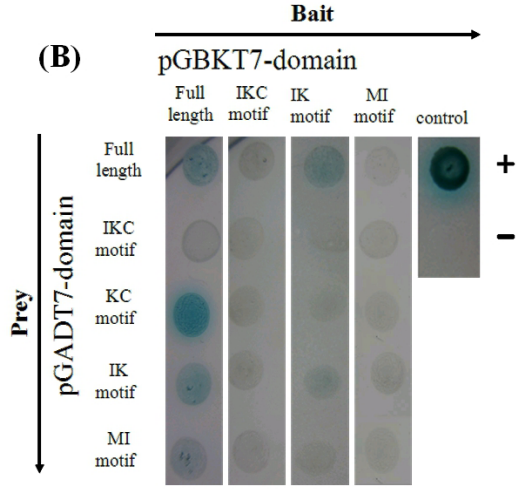

Figure 4. Yeast two-hybrid (Y2H) assay. A. Domain design. B. Y2H results. Schematic maps of bait and prey constructs used in the $\mathrm{Y} 2 \mathrm{H}$ assay are shown. Hybridization results are shown on SD/-Leu/-Trp/-His/-Ade+X-a-Gal. Control "+" refers to the positive control group: pGADT7-T and pGBKT7-53 hybridization. "-" refers to the negative control group: pGADT7-T and pGBKT7-lam.

\section{Conflicts of interest}

The authors declare no conflict of interest.

\section{ACKNOWLEDGMENTS}

Research supported by the National Natural Science Foundation of China (\#31270715 and \#31000295) and the Development Project from Zhejiang Agriculture and Forestry University (\#2010FR072).

\section{REFERENCES}

Agrawal GK, Abe K, Yamazaki M, Miyao A, et al. (2005). Conservation of the E-function for floral organ identity in rice revealed by the analysis of tissue culture-induced loss-of-function mutants of the OsMADS1 gene. Plant Mol. Biol. 59: 125-135.

Coen ES and Meyerowitz EM (1991). The war of the whorls: genetic interactions controlling flower development. Nature 353: 31-37. de Folter S, Immink RG, Kieffer M, Parenicova L, et al. (2005). Comprehensive interaction map of the Arabidopsis MADS Box transcription factors. Plant Cell 17: 1424-1433.

Huang H, Tudor M, Su T, Zhang Y, et al. (1996). DNA binding properties of two Arabidopsis MADS domain proteins: binding consensus and dimer formation. Plant Cell 8: 81-94.

Hwan Lee J, Joon Kim J and Ahn JH (2012). Role of SEPALLATA3 (SEP3) as a downstream gene of miR156-SPL3-FT circuitry in ambient temperature-responsive flowering. Plant Signal Behav. 7: 1151-1154.

Immink RG, Tonaco IA, de Folter S, Shchennikova A, et al. (2009). SEPALLATA3: the 'glue' for MADS box transcription factor complex formation. Genome Biol. 10: R24.

Jetha K, Theissen G and Melzer R (2014). Arabidopsis SEPALLATA proteins differ in cooperative DNA-binding during the formation of floral quartet-like complexes. Nucleic Acids Res. 42: 10927-10942. 
Kaufmann K, Muino JM, Jauregui R, Airoldi CA, et al. (2009). Target genes of the MADS transcription factor SEPALLATA3: integration of developmental and hormonal pathways in the Arabidopsis flower. PLoS Biol. 7: e1000090.

Krizek BA and Meyerowitz EM (1996). Mapping the protein regions responsible for the functional specificities of the Arabidopsis MADS domain organ-identity proteins. Proc. Natl. Acad. Sci. USA 93: 4063-4070.

Leseberg CH, Eissler CL, Wang X, Johns MA, et al. (2008). Interaction study of MADS-domain proteins in tomato. J. Exp. Bot. 59: 2253-2265.

Liu D, Wang D, Qin Z, Zhang D, et al. (2014). The SEPALLATA MADS-box protein SLMBP21 forms protein complexes with JOINTLESS and MACROCALYX as a transcription activator for development of the tomato flower abscission zone. Plant J. 77: 284-296.

Melzer R, Verelst W and Theissen $\mathrm{G}$ (2009). The class $\mathrm{E}$ floral homeotic protein SEPALLATA3 is sufficient to loop DNA in 'floral quartet'-like complexes in vitro. Nucleic Acids Res. 37: 144-157.

Mendes MA, Guerra RF, Berns MC, Manzo C, et al. (2013). MADS domain transcription factors mediate short-range DNA looping that is essential for target gene expression in Arabidopsis. Plant Cell 25: 2560-2572.

Pelaz S, Ditta GS, Baumann E, Wisman E, et al. (2000). B and C floral organ identity functions require SEPALLATA MADS-box genes. Nature 405: 200-203.

Pelaz S, Gustafson-Brown C, Kohalmi SE, Crosby WL, et al. (2001). APETALA1 and SEPALLATA3 interact to promote flower development. Plant J. 26: 385-394.

Puranik S, Acajjaoui S, Conn S, Costa L, et al. (2014). Structural basis for the oligomerization of the MADS domain transcription factor SEPALLATA3 in Arabidopsis. Plant Cell 26: 3603-3615.

Su K, Zhao S, Shan H, Kong H, et al. (2008). The MIK region rather than the C-terminal domain of AP3-like class $\mathrm{B}$ floral homeotic proteins determines functional specificity in the development and evolution of petals. New Phytol. 178: 544-558.

West AG, Causier BE, Davies B and Sharrocks AD (1998). DNA binding and dimerisation determinants of Antirrhinum majus MADS-box transcription factors. Nucleic Acids Res. 26: 5277-5287.

West AG, Shore P and Sharrocks AD (1997). DNA binding by MADS-box transcription factors: a molecular mechanism for differential DNA bending. Mol. Cell Biol. 17: 2876-2887.

Yang $Y$ and Jack $T$ (2004). Defining subdomains of the $\mathrm{K}$ domain important for protein-protein interactions of plant MADS proteins. Plant Mol. Biol. 55: 45-59.

Zhou Jiaping LX and Yingwu X (2014). Expression of Arabidopsis thaliana SEPALLATA3 protein in a prokaryotic system. J. Zhejiang AF Univ. 31: 5. 